\title{
X-ray crystal structure of a new triterpene, 3,23- cycloglutin-5(10)-ene from Euphorbia vajravelui
}

\author{
Vijayalekshmi Anju and Koranappallil Bahuleyan Rameshkumar* \\ Phytochemistry and Phytopharmacology Division, KSCSTE-Jawaharlal Nehru Tropical Botanic Garden and Research Institute, \\ Pacha-Palode, Thiruvananthapuram 695 562, India
}

\begin{abstract}
Euphorbia species are known for their diversity of terpenoid constituents. Euphorbia vajravelui is an endemic plant species distributed in the southern Western Ghats of India. Though conventional spectroscopic techniques are common in structure elucidation of secondary metabolites from plants, X-ray crystal structure analysis of a compound offers valuable information with minimum sample requirement. The present study reports the characterization of a new triterpene, 3,23-cycloglutin-5(10)-ene isolated from $E$. vajravelui, using single-crystal X-ray diffraction studies. Triclinic crystalline system was obtained for the compound, having P1 space group with unit cell parameters; $a=6.2907(8) \AA, b=7.4458(10) \AA, c=$ 14.5802(18) $\AA, \quad \alpha=94.899(6)^{\circ}, \quad \beta=95.365(6)^{\circ}, \quad \gamma=$ $114.392(6)^{\circ}, V=613.43(14) \AA^{3}$ and $Z=1$. The triterpene has a glutinane skeletal structure containing a cyclopropane ring with a methyl group.
\end{abstract}

Keywords: Euphorbia vajravelui, glutinane skeleton, terpenoid constituents, triterpene, X-ray crystal structure.

EUPHORBIA VAJRAVELUI Binojk. \& N. P. Balakr. is an endemic plant, distributed in the southern Western Ghats of Kerala and Tamil Nadu, India ${ }^{1}$. Euphorbia species are known for the diversity of terpenoid constituents with friedelane, oleanane, ursane, taraxerane, cycloartane, glutinane,

lupane, euphane and tirucallane skeletons ${ }^{2}$. Triterpenes such as glutin-5-en-3-one (alnusenone or glutinone) and glutin-5-en-3-ol, having glutinane skeletons have been previously reported from Euphorbia cyparissias, Euphorbia watanabei and Euphorbia segetalis ${ }^{3-5}$. Compounds with glutin-5(10)-ene skeleton such as glutin-5(10)-en$3 \beta$-yl acetate (alnus-5(10)-en-3 $\beta$-yl acetate), glutin-5(10)en-3 $\beta$-ol (alnus-5(10)-en-3 $\beta$-ol), $3 \beta$-acetoxyglutina-5(10), 6-dien-27,8 $\alpha$-olide, $3 \beta$-(benzoyloxy)glutina-5(10),6-dien$27,8 \alpha$-olide and $3 \beta$-[(2-hydroxybenzoyl)oxy]glutina-5(10), 6 -dien-27,8 $\alpha$-olide have been reported from different plant sources ${ }^{6,7}$. Glutin-5(10)-ene[D:B-friedoolean-5(10)ene] is a stable intermediate in the friedelene-oleanene rearrangement and can be isolated from the reaction mix-

*For correspondence. (e-mail: kbr@jntbgri.res.in) ture $^{8}$. Preparation of glutin-5(10)-en-1-one and similar compounds is reported by Akiyama et al. ${ }^{9}$. A cyclopropane ring with a methyl group in a typical pentacyclic triterpenoid skeletal structure is rare in contrast to tetracyclic triterpenoids like cycloartanes. Previous reports of pentacyclic triterpenoids containing a cyclopropane ring include phyllanthol (13,27-cycloursan-3 $\beta$-ol) and phyllanthone $(13,27 \text {-cycloursan-3-one })^{10,11}$. Pentacyclic triterpenoids such as taraxeryl acetate, epi-friedelinyl acetate, $3 \beta$-friedelinol, taraxerol, $3 \alpha$-friedelinol and friedelane$2 \beta, 3 \alpha$-diyldiacetate have been previously reported from $E$. vajravelui ${ }^{12}$. The present study reports the isolation and X-ray crystal structure of a triterpene with a cyclopropane ring from E. vajravelui.

\section{Materials and methods}

\section{Plant material}

Aerial parts of E. vajravelui were collected from the campus of the Jawaharlal Nehru Tropical Botanic Garden and Research Institute (JNTBGRI), Thiruvananthapuram, and authenticated by R. Raj Vikraman, from the Institute. A voucher herbarium specimen (TBGT No. 81424) has been deposited at the Institute Herbarium.

\section{Extraction and isolation}

The dried powder of E. vajravelui (475 g) was extracted with $n$-hexane in a Soxhlet apparatus. The hexane extract $(30 \mathrm{~g})$ was fractionated by silica gel (60-120 mesh) column chromatography applying gradient elution with $n$-hexane and chloroform. The first fraction obtained in $100 \% n$-hexane was again fractionated by column chromatography using silica gel (100-200 mesh) and $n$-hexane as the eluting solvent to afford the compound. The compound gave positive test for terpenoid with Liebermann-Burchard reagent, and an $R_{f}$ value of 0.80 in reverse phase thin layer chromatography using the solvent system chloroform and methanol in the ratio $6: 4$. A sharp white crystal of the compound suitable for X-ray diffraction analysis was made by recrystallization in chloroform at room temperature. 
Table 1. Crystal data and structure refinement

\begin{tabular}{|c|c|}
\hline Chemical formula: $\mathrm{C}_{30} \mathrm{H}_{48}$ & $F(000)=228$ \\
\hline Formula weight $=408.68$ & $D_{\mathrm{x}}=1.106 \mathrm{Mg} \mathrm{m}^{-3}$ \\
\hline \multicolumn{2}{|l|}{ Crystal system and space group: Triclinic, P1 } \\
\hline \multicolumn{2}{|l|}{ Unit cell dimensions } \\
\hline$a=6.2907(8) \AA$ & Radiation type: MoK $\alpha$ radiation, $\lambda=0.71073 \AA$ \\
\hline$b=7.4458(10) \AA$ & Cell parameters from 5931 reflections \\
\hline$c=14.5802(18) \AA$ & $\theta=2.8-28.5^{\circ}$ \\
\hline$\alpha=94.899(6)^{\circ}$ & $\mu=0.06 \mathrm{~mm}^{-1}$ \\
\hline$\beta=95.365(6)^{\circ}$ & $T=296 \mathrm{~K}$ \\
\hline$\gamma=114.392(6)^{\circ}$ & Block, colourless \\
\hline$V=613.43(14) \AA^{3}$ & Crystal size: $0.24 \times 0.15 \times 0.15 \mathrm{~mm}$ \\
\hline \multicolumn{2}{|l|}{$Z=1$} \\
\hline \multicolumn{2}{|l|}{ Data collection } \\
\hline Diffractometer: Bruker KAPPA APEX-II CCD & 8959 measured reflections \\
\hline Source of radiation: sealed tube & 4208 independent reflections \\
\hline Resolution of detector: 0 pixels $\mathrm{mm}^{-1} \varphi$ and $\omega$ scans & 3970 reflections with $I>2 \sigma(I)$ \\
\hline Absorption correction: multi-scan SADABS & $R_{\text {int }}=0.017$ \\
\hline \multirow[t]{4}{*}{$T_{\min }=0.985, T_{\max }=0.990$} & $\theta_{\max }=25.0^{\circ}, \theta_{\min }=2.8^{\circ}$ \\
\hline & $h=-7 \rightarrow 7$ \\
\hline & $k=-8 \rightarrow 8$ \\
\hline & $l=-17 \rightarrow 17$ \\
\hline Refinement & Hydrogen site location: determined from neighbouring sites \\
\hline Refinement on $F^{2}$ & $\mathrm{H}$-atom parameters constrained \\
\hline Least-squares matrix: full & $w=1 /\left[\sigma^{2}\left(F o^{2}\right)+(0.0846 P)^{2}+0.0656 P\right]$ \\
\hline$R\left[F^{2}>2 \sigma\left(F^{2}\right)\right]=0.043, w R\left(F^{2}\right)=0.125$ & where $P=\left(F o^{2}+2 F c^{2}\right) / 3$ \\
\hline$S=1.03$ & $(\Delta / \sigma)_{\max }<0.001$ \\
\hline 4208 reflections & $\Delta \rho_{\max }=0.416 \mathrm{e}^{-3}$ \\
\hline 278 parameters & $\Delta \rho_{\min }=-0.1683 \mathrm{e}^{-3}$ \\
\hline 3 restraints & \\
\hline
\end{tabular}

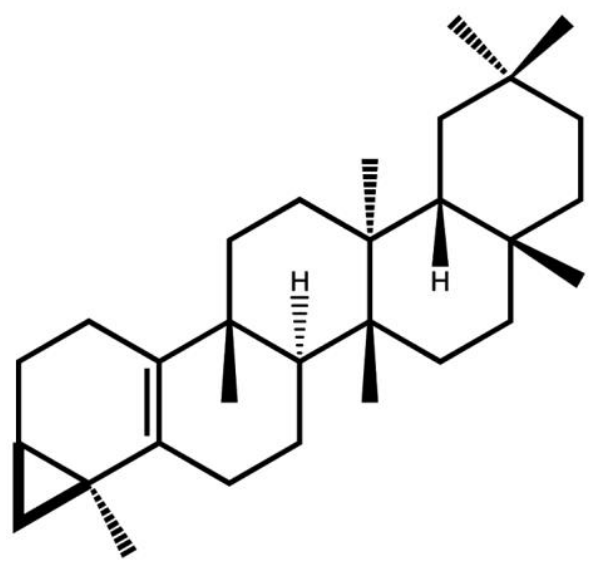

Figure 1. Structure of 3,23-cycloglutin-5(10)-ene.

\section{Single crystal XRD}

Computing details: Data collection: APEX2 (ref. 13); cell refinement: APEX2/SAINT ${ }^{13}$; data reduction: SAINT/ XPREP $^{13}$; program used to solve structure: SHELXL2014 (ref. 14); program used for structure refinement: SHELXL2014 (ref. 14); molecular graphics: ORTEP-3 (ref. 15) and Mercury ${ }^{16}$; software used to prepare material for publication: SHELXL2014 (ref. 14).
Refinement: All the atoms other than hydrogen were anisotropically refined. The positions of hydrogen atoms were determined from Fourier difference maps and placed geometrically, and treated with a riding model. At the end of refinement, the highest peak of residual electron density was found to be $0.416 \mathrm{e} / \AA^{3}$ and deepest hole was $-0.1683 \mathrm{e} / \AA^{3}$.

\section{Results and discussion}

Single crystal X-ray diffraction (SXRD) data gave the structure of the crystal as 3,23-cycloglutin-5(10)-ene, an uncommon triterpene containing a cyclopropane ring with a methyl group (Figure 1). Table 1 lists the crystallographic data. The molecular formula $\left(\mathrm{C}_{30} \mathrm{H}_{48}\right)$ and formula weight (408.68) were elucidated from the crystallographic data. Carbon, Hydrogen, Nitrogen and Sulphur (CHNS) analysis $(\% \mathrm{C}-88.01$ and $\% \mathrm{H}-11.78$; calculated: $\% \mathrm{C}-88.16$ and $\% \mathrm{H}-11.84)$ also supported the suggested molecular formula. The crystallized triclinic system had P1 space group with one molecule per unit cell. The unit cell dimensions were $a=6.2907(8) \AA, b=7.4458(10) \AA$ and $c=14.5802(18) \AA, \alpha=94.899(6)^{\circ}, \quad \beta=95.365(6)^{\circ}$ and $\gamma=114.392(6)^{\circ}$. Volume $(V)=613.43(14) \AA^{3}$, density $($ calculated $)=1.106 \mathrm{Mg} / \mathrm{m}^{3}$ and crystal size was $0.240 \times$ $0.150 \times 0.150 \mathrm{~mm}$. Figure 2 depicts the Oak Ridge 
Thermal Ellipsoid Plot (ORTEP) diagram and atom labelling of the compound. Supplementary Table 1 shows the bond lengths and bond angles. The atomic coordinates and their equivalent isotropic thermal factors are presented in the Supplementary Table 2. Crystallographic data of the compound have been deposited in the Cambridge Crystallographic Data Centre (CCDC1571973; www.ccdc.cam.ac.uk). Further spectral details (IR, NMR and mass) are provided in the Supplementary Material.

The triterpene characterized in the present study has a glutinane skeletal structure. Crystal structures of triterpenes having glutinane and similar skeletal structures have been previously reported. Ohki et al. ${ }^{17}$, reported the crystal structure of glutinone or alnusenone (D:Bfriedoolean-5-en-3-one) having space group P1. Connolly

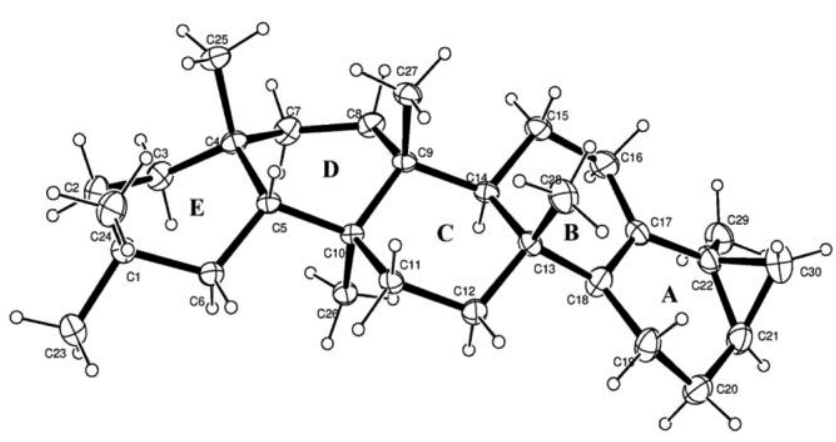

Figure 2. ORTEP diagram of 3,23-cycloglutin-5(10)-ene showing the atom numbering scheme.

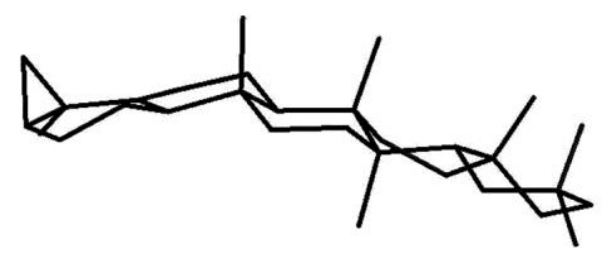

Figure 3. Stereoview of the molecule showing conformation.

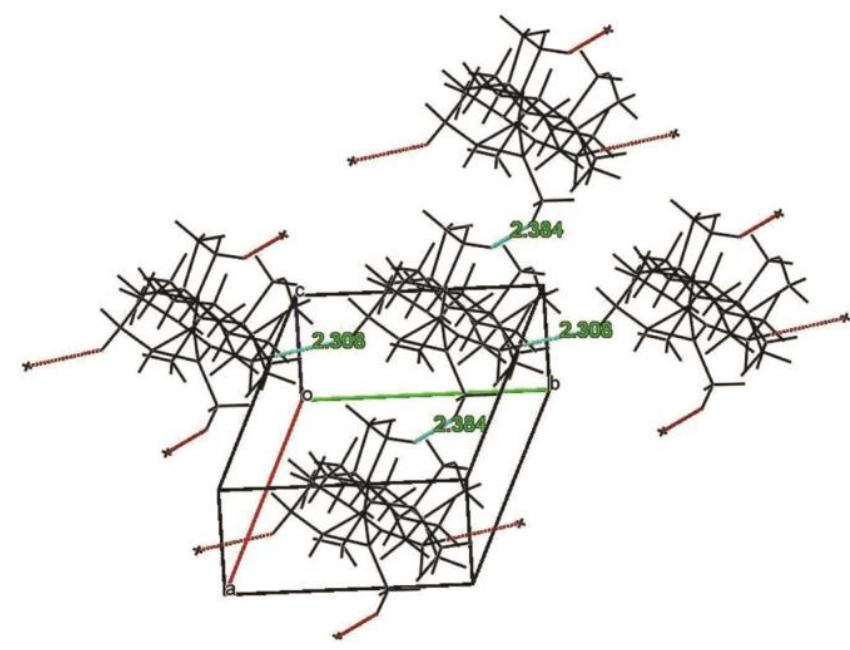

Figure 4. Packing diagram viewed through the $b$-axis. et $a l .{ }^{18}$ reported the crystal structure of a novel triterpenoid $5 \beta, 24$-cyclofriedelan-3-one having space group $\mathrm{P} 1$. $\mathrm{X}$-ray crystallographic data of both these compounds are comparable to the present data, confirming the skeletal structure of 3,23-cycloglutin-5(10)-ene. Here the compound consists of five six-membered rings (A-E) with seven tertiary methyl groups; five methyl groups (C-24$\mathrm{C}-28$ ) and the cyclopropane ring were in the axial position (Figures 2 and 3). Ring A orients in a twist boat form, due to the torsional constraints of the cyclopropane group. Rings $\mathrm{B}$ and $\mathrm{C}$ both adopt chair forms, while rings $\mathrm{D}$ and $\mathrm{E}$ adopt a twist boat and boat form respectively; both are cis-fused (Figure 3). Such features are also found in the crystal structure of triterpenes such as epifriedelinol and glutinone (alnusenone) ${ }^{19,20}$.

In the molecule, all bond distances and bond angles appeared to be within the usual range (Supplementary Table 1). All the $\mathrm{Csp}^{3}-\mathrm{Csp}^{3}$ bond lengths were in the range $1.470-1.587 \AA$ and $\mathrm{Csp}^{3}-\mathrm{H}$ bonds in the range $0.960-0.980 \AA$, as expected. The bond angle corresponding to the cyclopropane ring system $(\mathrm{C}(22)-\mathrm{C}(21)-\mathrm{C}(30)$, $\mathrm{C}(30)-\mathrm{C}(22)-\mathrm{C}(21)$ and $\mathrm{C}(22)-\mathrm{C}(30)-\mathrm{C}(21))$ was observed within the range $58.0^{\circ}-61.9^{\circ}$. The region $\mathrm{C} 16-$ C17-C18-C13 was nearly planar (Figure 2), showing some electron delocalization and resonance. Ideally $\mathrm{C} 17-$ C18 should be a double bond (1.34 $\AA$ ) and C16-C17 should be $\left(\mathrm{Csp}^{2}-\mathrm{Csp}^{3}\right)$ a single bond $(\sim 1.51 \AA)$. However, the actual bond distances of $\mathrm{C} 16-\mathrm{C} 17$ and $\mathrm{C} 17-\mathrm{C} 18$ were in the range $1.42 \AA$, which shows some single- and double-bond resonance between $\mathrm{C} 16-\mathrm{C} 17$ and $\mathrm{C} 17-\mathrm{C} 18$. Two hydrogen atoms should be involved for balancing the valency. One hydrogen should be always with C16 and the other hydrogen (ideally) shared between C16 and C18. Since the moiety is near-planar, both hydrogens will be at $\mathrm{C} 16$ and the double bond is preferred at $\mathrm{C} 17-\mathrm{C} 18$ (Figure 2).

Inter- and intramolecular hydrogen bonds were absent due to the lack of electronegative atoms like oxygen, nitrogen, etc. in the molecule. Only weak, short-contact interactions were found in the molecule. In the crystal, each molecule was connected with four others through short intermolecular bonds observed within the range 2.308-2.384 $\AA$ (Figure 4). Figure 4 shows the packing viewed through the $b$-axis.

\section{Conclusion}

The present study reports the isolation and characterization of a new triterpene 3,23-cycloglutin-5(10)-ene from the aerial parts of E. vajravelui. The triterpene contains an unusual glutinane skeleton having a cyclopropane ring, together with a methyl group. The single-crystal $\mathrm{X}$-ray diffraction has been proven as an efficient tool in the structure elucidation of such unusual structural systems. 
1. Balakrishnan, N. P. and Chakrabarty, T., The Family Euphorbiaceae in India: A Synopsis of its Profile, Taxonomy and Bibliography, Bishen Singh Mahendra Pal Singh, Dehra Dun, 2007.

2. Shi, Q. W., Su, X. H. and Kiyota, H., Chemical and pharmacological research of the plants in genus Euphorbia. Chem. Rev., 2008 , 108, 4295-4327.

3. Rizk, A. F. M., The chemical constituents and economic plants of the Euphorbiaceae. Bot. J. Linn. Soc., 1987, 94, 293-326.

4. Starratt, A. N., Triterpenoid constituents of Euphorbia cyparissias. Phytochemistry, 1966, 5, 1341-1344.

5. Madureira, A. M., Ascenso, J. R., Valdeira, L., Duarte, A., Frade, J. P., Freitas, G. and Ferreira, M. J. U., Evaluation of the antiviral and antimicrobial activities of triterpenes isolated from Euphorbia segetalis. Nat. Prod. Res., 2003, 17, 375-380.

6. Hsu, C. L., Fang, S. C., Huang, H. W. and Yen, G. C., Antiinflammatory effects of triterpenes and steroid compounds isolated from the stem bark of Hiptage benghalensis. J. Funct. Foods, 2015, 12, 420-427.

7. Lee, S. S., Kishore, P. H. and Chen, C. H., Three novel triterpenoiddienolides from Phyllanthus myrtifolius. Helv. Chim. Acta, 2002, 85, 2403-2408.

8. Courtney, J. L., Gascoigne, R. M. and Szumer, A. Z., Triterpenes of the friedelane series. Part III. The course of the friedeleneoleanene rearrangement. J. Chem. Soc. (Resumed), 1958, 881-886.

9. Akiyama, E., Moriyama, Y., Murae, T., Tsuyuki, T. and Takahashi, T., Preparation of D:B-Friedoolean-5(10)-en-1-one and related compounds. A comment on the structure of glut-5(10)-en1-one from Euphorbia nerifolia. Bull. Chem. Soc. Jpn., 1978, 51, 2702-2704.

10. Alberman, K. B. and Kipping, F. B., Phyllanthol. A new alcohol from the root bark of Phyllanthus engleri (Pax). J. Chem. Soc. (Resumed), 1951, 2296-2297.

11. Ndlebe, V. J., Crouch, N. R. and Mulholland, D. A., Triterpenoids from the African tree Phyllanthus polyanthus. Phytochem. Lett. 2008, 1, 11-17.

12. Anju, V., Priya, S., Sabulal, B. and Rameshkumar, K. B., Chemical constituents and cytotoxicity of Euphorbia vajravelui. Lett. Org. Chem., 2019, 16, 643-646.

13. Bruker, APEX2, SAINT and SADABS, Bruker AXS Inc., Madison, Wisconsin, USA, 2004.
14. Sheldrick, G. M., Crystal structure refinement with SHELXL. Acta Crystallogr. Sect. C, 2015, 71, 3-8.

15. Farrugia, L. J., ORTEP-3 for Windows - a version of ORTEP-III with a graphical user interface (GUI). J. Appl. Crystallogr., 1997, 30, 565 .

16. Bruno, I. J. et al., New software for searching the Cambridge Structural Database and visualizing crystal structures. Acta Crystallogr. Sect. B, 2002, 58, 389-397.

17. Ohki, M., Tachibana, K., Kuroda, T., Takenaka, A. and Sasada, Y., Structure of alnusenone (D:B-friedoolean-5-en-3-one). Acta Crystallogr. Sect. B, 1981, 37, 2092-2094.

18. Connolly, J. D., Freer, A. A., Anjaneyulu, V., Ravi, K. and Sambasivarao, G., Structure of 5 $\beta, 24$-cyclofriedelan-3-one, a novel hexacyclic triterpenoid in space group P1. Acta Crystallogr. Sect. C, 1986, 42, 1352-1354

19. Masaki, N., Niwa, M. and Kikuchi, T., Studies on the neutral constituents of Pachysandra terminalis Sieb. etZucc. Part IV. X-ray structure of 3-O-acetyl-16-O-p-bromobenzoylpachysandiol B: new conformation of a friedelin-type triterpene. J. Chem. Soc. Perkin Trans. 2, 1975, 610-614.

20. Rogers, D., Phillips, F. L., Joshi, B. S. and Viswanathan, N., Revised structures of the triterpenes $\mathrm{Q}, \mathrm{T}$, and $\mathrm{U}$ from Salacia prinoides DC; X-ray crystal structure of triterpene T. J. Chem. Soc. Chem. Commun., 1980, 22, 1048-1049.

ACKNOWLEDGEMENTS. We thank Prof. (Dr) M. R. Prathapachandra Kurup (Department of Chemistry, School of Physical Science, Central University of Kerala, Kasaragod), and Dr M. R. Sudarsanakumar (Former Principal, Mahatma Gandhi College, Thiruvananthapuram), for their interpretation of SXRD data. We also thank Mr P. Alex Andrews (IISER, Thiruvananthapuram), for SXRD analysis and Dr Mathew Dan (Plant Genetic Resources Division, JNTBGRI, Thiruvananthapuram) for providing the plant material, Euphorbia vajravelui.

Received 18 September 2020; revised accepted 1 February 2021

doi: $10.18520 / \mathrm{cs} / \mathrm{v} 120 / \mathrm{i} 10 / 1623-1626$ 